
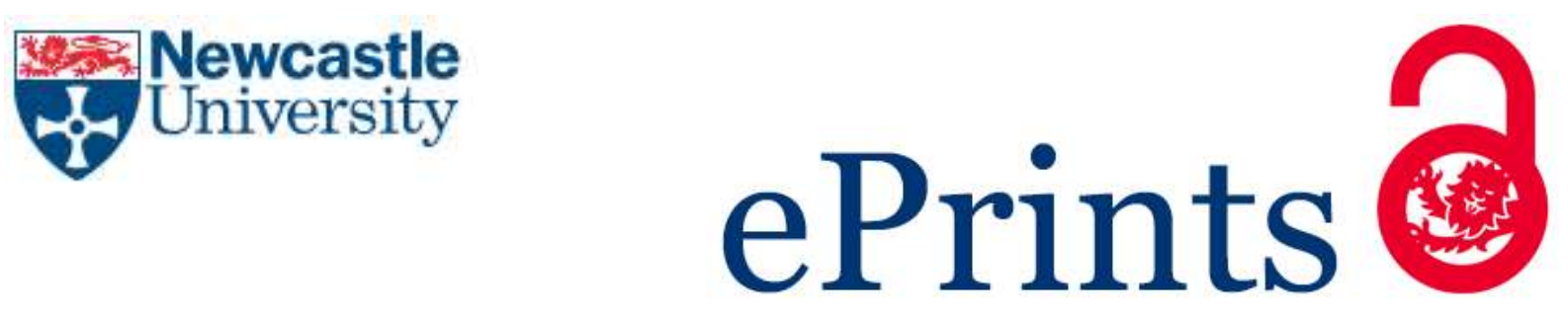

Robson S, Almeida J, Schartner A. Internationalization at Home: time for review and development?. European Journal of Higher Education 2017

\title{
Copyright:
}

This is an Accepted Manuscript of an article published by Routledge in European Journal of Higher Education on $12^{\text {th }}$ October 2017, available online: https://doi.org/10.1080/21568235.2017.1376697

Date deposited:

$08 / 12 / 2017$

Embargo release date:

12 April 2019

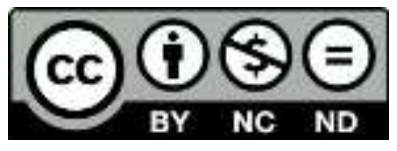

This work is licensed under a

Creative Commons Attribution-NonCommercial-NoDerivatives 4.0 International licence 


\title{
Internationalisation at home: time for review and development?
}

\author{
Sue Robson, Joana Almeida, Alina Schartner
}

School of Education, Communication and Language Sciences, Newcastle University, Newcastle, UK.

sue.robson@ncl.ac.uk

Sue Robson is Professor of Education at Newcastle University where she leads a Teaching and Learning in Higher Education Research Group. Her research interests include the internationalisation of higher education and its impacts on teaching, learning and university culture and values.

Joana Almeida is a Research Associate at Newcastle University where she develops research in the internationalisation of higher education and intercultural communication. She holds a $\mathrm{PhD}$ in Education from the University of Aveiro, Portugal, and was a visiting scholar at SIT Graduate Institute, USA. She is a former Erasmus student and member of the Erasmus Student Network Aveiro.

Alina Schartner is Lecturer in Applied Linguistics at Newcastle University where she teaches and researches intercultural communication. Her research interests include the internationalisation of higher education and the social psychology of communication. She is currently serving as Secretary of the International Association of Language and Social Psychology (IALSP). 


\section{Internationalisation at home: time for review and development?}

Internationalisation is a key contemporary debate within Higher Education (HE). Many universities worldwide proclaim their 'international' status, citing quantitative indicators, particularly international student and staff recruitment and outbound student mobility data to illustrate this. In this paper, we focus on the non-mobile majority of the academic community. We foreground internationalisation at home ( $\mathrm{IaH})$ and the underlying social, academic and intercultural learning benefits of an internationalised university experience. We explore how IaH is understood and operationalised in two universities in the United Kingdom and Portugal via a multiple case study. Qualitative data from 12 stakeholder interviews are analysed, generating five themes about operational understandings and practices of IaH. Findings identify relevant explanatory factors that may assist other institutions to understand, enact and communicate about IaH. We highlight the need for further empirical research to provide insights into how this key dimension of internationalisation is being operationalised across other European HE institutions.

Keywords: internationalisation; at home; higher education.

\section{Introduction}

Internationalisation is one of the key contemporary debates within the HE sector. For the last two decades, many universities worldwide have proclaimed their 'international' status, but there has been little consensus about how this status can be defined. In many HE institutions, internationalisation has been associated with increased market share of international students and staff, numbers of outwardly mobile students, and numbers of international partnerships, in efforts to enhance institutional prestige and global ranking (Lumby and Foskett, 2016). The preoccupation with market position, and the reliance on metrics as a proxy for quality are worrying but perhaps inevitable trends, given the political and economic drivers for internationalisation in an increasingly volatile international HE landscape (Egron-Polak, 2012; Seeber et al., 2016; Hazelkorn, 2016). Powerful regional HE hubs are emerging, for example, the five major emerging national 
economies: Brazil, Russia, India, China and South Africa (BRIC countries). New technologies are developing at a rapid pace, with universities competing to "play a central role in developing creative and social intelligence skills in ...students so that they might have viable talents for future labor markets'(Tierney and Landford, 2016, p3).

In this competitive climate an alternative discourse has called for internationalisation strategies and processes to be approached with integrity (Inan et al., 2014). With greater emphasis placed on the ethical, social, cultural and academic goals (Pashby and Andreotti, 2016), internationalisation can contribute to the quality and relevance of HE (Urban and Palmer, 2013; Henard et al., 2012; de Wit et al., 2015). One of the key challenges for the internationalisation of higher education (IoHE) is to develop international and cross-cultural perspectives and understandings among students, to prepare them for their role in a globalised workplace, and in an increasingly global knowledge economy (Altbach, 2013).

A number of earlier European IoHE projects have sought to 'provide the most relevant education to students who will be the citizens, entrepreneurs and scientists of tomorrow' (Henard et al., 2012, p.7) by focusing on transnational mobility. This paper focuses on IaH as an important dimension of IoHE, in line with the goals of the Europe 2020 Growth Strategy, to internationalise the experiences and mind-sets of the nonmobile majority (deWit et al., 2015).

IaH is not a new concept: the European Association for International Education IaH Special Interest Group was established in 1999, a time when 'international migration was on the rise everywhere and the limitations to a further expansion of physical mobility existed all over Europe' (Wachter, 2003, p.6). There are interesting parallels to the current geopolitical circumstances. Dialogue around IaH is gathering a 
renewed momentum as the values, purposes, and means of IoHE are re-examined (Jones, 2014; de Wit et al., 2015; Yemini and Sagie, 2015; Beelen and Jones, 2015; Harrison, 2015).

There is to date no recognised strategy, formula or approach to IaH, although important elements have been identified. Related to other reform and innovation trends in HE such as comprehensive internationalisation (Hudzik, 2011) and internationalisation of the curriculum (Leask, 2015), IaH has the potential to "enhance these as they will reinforce IaH' (Wachter, 2003, p.10). IaH has been recently defined as the 'purposeful integration of international and intercultural dimensions into the formal and informal curriculum for all students within domestic learning environments' (Beelen \& Jones, 2015, p.76).

Faculty are crucial contributors to IaH (Bedenlier and Zawacki-Richter, 2015). Professional development opportunities are important to support the delivery of culturally sensitive pedagogies and internationalised curricula. Finding ways to contextualise internationalised learning outcomes in programmes of study and assessment criteria 'at home', for students who have limited contact with other forms of internationalisation is an ongoing challenge (Jones 2014; Jones and Killick 2013; Beelen and Jones, 2015). This can help to ensure that students have opportunities to deeply engage with global issues and each other (Crowther et al. 2000; Nilsson, 2003; Seeber et al., 2016)-and each other, to develop from 'discrete social groupings into a eohesive whole, not merely co-located but interacting' (Economist Intelligence Unit, 2016, p.19).Opportunities to learn foreign languages and engage in 'virtual mobility' through digital learning can enhance interactions with staff and peers from other cultures, facilitating the development of 'global mindsets' (Jones and Killick, 2013).This can nurture 'a greater capacity to manage difference, change and 
complexity' (Marginson, 2017), and a greater level of comfort with 'plural cultures' (Mak, 2010; EAIE, 2016; European Parliament, 2016).

This paper explores understandings and practices of IaH in two public universities, one in Portugal and the other in the UK. It presents a multiple case study of the perceptions of staff at these universities on how the vision for internationalisation at their institution is enacted in policy and practice. It specifically explores how IaH is understood and operationalised, with the aim of identifying relevant explanatory factors that might be useful to other institutions seeking to review the ways in which they develop, enact and communicate IaH.

\section{Policy context}

IoHE is rising in strategic importance among European HE institutions, the majority of which claim to have an internationalisation strategy in place or to have included internationalisation as an element of their overall institutional strategy (Sursock, 2015, p.30). The EU called for close cooperation between the EU, Member States and HE institutions to develop 'sophisticated internationalization strategies for cooperation with partners in other parts of the world, not only in terms of student mobility but also at the level of strategic academic partnerships' to address global challenges (European Commission, 2013). Several European-level projects to date have provided tools for mapping internationalisation practices (EUA, 2012, 2013) and to develop intercultural competences in internationally mobile learners (IEREST, 2012-2015; Almeida, 2015).

A renewed focus on IaH to promote the more social and values-based goals of IoHE for all students seems timely. Recent political events in the UK (the Brexit vote), America (the presidential election) and Europe (with political unrest arising from the large-scale migration of thousands of people fleeing conflict) have revealed deeply 
rooted social schisms. Universities may deploy IaH to address attitudes towards political or economic, religious or cultural, ethnic or linguistic conflict in fractured societies (Marantz-Gal, 2016; Marginson, 2017), and as a means to develop the analytical and personal abilities and dispositions that underpin an active and responsible contribution in globalised, knowledge-based economies (Barker and Mak, 2013). In proposing the timeliness of institutional review and development of IaH practices, the paper directly addresses Key Priority Area 2 of the European Commission's Communication on European Higher Education in the World: 'Promoting internationalisation at home' (2013).

\section{The study}

This study employs a multiple-case study design to investigate a contemporary phenomenon in-depth and within its real-life context (Yin, 2014). It does so by integrating two independent research studies with the common goal of understanding internationalisation processes and/or activities in HE settings. Whereas case study 1 addresses these processes at a British University (UK) and is part of an ongoing Erasmus+ project, case study 2 is a completed doctoral research (Almeida, 2015) addressing similar issues at a Portuguese University (PT). The rationale for selecting the case studies is that both institutions are research-intensive public universities, with internationalisation and international attractiveness as key priorities. The British university is among the top 20 recruiters of international students in the UK (UKCISA, 2016), and around $20 \%$ of its workforce are non-UK. The Portuguese institution is one of the 14 public universities in Portugal enrolling on average 15,000 students a year. In terms of international student recruitment, the institution emerges mainly as a net importer of credit- seeking students, particularly through the EU flagship programme Erasmus+, but also of degree-seeking students from Portuguese-speaking countries, 
especially Undergraduate and Master's students from Portuguese-speaking African countries.

The study has two research objectives:

(1) To explore how internationalisation practices are approached and operationalised in the two case study institutions in the UK and Portugal

(2) To identify IaH practices in the two institutions and relevant explanatory factors.

\section{Methods of data collection and analysis}

Data were collected through 12 individual semi-structured interviews (lasting $52 \mathrm{~min}$ on average) with stakeholders in the two institutions. All interviews were audio-recorded with the informed consent of research participants and systematic summary notes were derived from the recordings. Selective data were transcribed verbatim to give 'voice' to the participants (Corden and Sainsbury, 2006). A thematic analysis was then applied to the transcripts and summary notes. Thematic analysis is understood here as a process of systematic pattern recognition within data set(s) wherein themes which capture the richness of the phenomenon of interest become the categories for analysis (Boyatzis, 1998; Fereday \& Muir-Chochrane, 2006). A theme emerges, thus, as the basic coding unit or pattern which "at minimum describes and organizes possible observations, and at maximum interprets aspects of the phenomenon" (Boyatzis, 1998, p. 4).

Selection of this data analysis method followed three criteria: (1) the exploratory nature of our study, (2) the two voluminous data sets, and (3) the flexibility of performing within- and cross-case analyses. 
Analysis encompassed both inductive and deductive approaches. The inductive themes emerged from the data whereas deductive themes were based on specialised literature about the IoHE.

The analytical process was iterative, beginning with (re)familiarization with raw data, followed by manual and electronic data management, and comparison to identify common themes in the data sets.

\section{Participants}

The 12 participants include 8 stakeholders from case study 1 (5 males, 3 females) and 4 from case study 2 ( 2 males, and 2 females). Given the uneven number of interviewees, $66 \%(n=8)$ of the data in this paper is generated from UK, and $33 \%(n=4)$ from PT. Similarities of interviewee roles and involvement in internationalisation processes was sought to ensure comparability of data.

The depiction of the 12 interviewees as stakeholders is based on a definition from stakeholder theory (see Freeman, 1984) and on studies which apply this notion to European HE governance (e.g., Amaral \& Magalhães, 2002) and to internationalisation processes in particular (e.g., Almeida, 2015; Castro, Rosa, \& Pinho, 2015). We therefore define stakeholders as:

Higher education agents who have a legitimate interest and/or stake in internationalisation processes and its activities and can, therefore affect or be affected by the achievements of the organization's objectives, rationales and incentives in this respect (Almeida, 2015; Amaral \& Magalhães, 2002; Castro et al., 2015).

With this definition in mind, we identified stakeholders across different professional responsibilities and/or roles related to internationalisation at the two institutions (Table 1Table 1). The criterion for selecting participants was twofold: 
1. Relative influence and different levels of involvement in internationalisation development at the institution;

2. Representativeness across top-down and bottom-up approaches to internationalisation at the institution.

Table 1 - Interviewee roles and/or responsibilities.

\begin{tabular}{lcc}
\hline Stakeholder roles and/or responsibilities & N & $\%$ \\
\hline Senior Management & 4 & 33 \\
Learning and Teaching Committees & 3 & 25 \\
Student Service Unit Officer & 2 & 17 \\
Student Service Manager & 2 & 17 \\
Representatives of EU projects & 1 & 8 \\
\hline TOTAL & 12 & 100 \\
\hline
\end{tabular}

\section{Data analysis and discussion}

Data analysis followed a cross-case synthesis logic to aid the comparison of commonalties and differences across data patterns yielded by the case studies whilst capturing the individual perspectives of interviewees. This analytical technique is consistent with the multiple-case study design and the robustness of findings sought (Yin, 2014). Each case study was treated as a distinct unit of analysis but findings were aggregated around five analytical themes, i.e. the set of factors shared by the case studies. These themes and underlying descriptors are represented in Table 2Table 2.

Table 2 - Themes and descriptors.

\begin{tabular}{ll}
\hline Code Themes & Descriptors \\
\hline
\end{tabular}

1 Status quo of internationalisation processes
Stage of the process of integrating an international, intercultural, or global dimension into the purpose, functions and delivery ${ }^{1}$ of the institution; prioritising geographical areas or target countries; predominant rationales for internationalisation 
2 Indicators of internationalisation

3 Internationalised curricula and/or intercultural pedagogies

4 Professional development

5 Student (on-campus) experience
Measurable factors used as representation of the state or level of institutional internationalisation processes

Relative importance of internationalised curricula and/or pedagogies within institutional internationalisation processes

Professional development opportunities to support the delivery and assessment of culturally sensitive pedagogies and/or internationalised curricula; including staff roles and responsibilities outcomes

Socio-cultural and communal aspects of the student university experience on campus: integration of home and international students and the role of student services in it

Note $^{l}$. The definition of internationalisation is based on the work of Knight (2004)

In the next section we discuss the themes outlined in Table 2Table 2 against relevant excerpts. Selection of verbatim excerpts is based on their range and relevance to the targeted theme.

\section{Theme 1: Status quo of internationalisation processes}

Theme 1 addresses the development of institutional internationalisation processes and underlying activities and/or strategies in light of the intricate mix of academic, political, socio-cultural and economic rationales that inform these efforts. This encompasses cross-border and at-home activities which are here seen as two interdependent pillars, since cross-border education has implications for campus-based internationalisation and vice versa (Knight, 2004, 2012).

Stakeholders across the two case studies perceived internationalisation as an academic asset and as a question of survival in an increasingly globalised world where both institutions strive for a strong national and international positioning, as evident in

\section{Table 3Table 3:}

Table 3 - Theme 1: Descriptors and excerpts. 


\begin{tabular}{|c|c|c|}
\hline Descriptors & Case 1 & Case 2 \\
\hline \multirow[b]{2}{*}{ Rationales } & $\begin{array}{l}\text { The overreliance on international } \\
\text { students brings a question of what } \\
\text { internationalisation is...Is it a necessity } \\
\text { because of finance? Or is it something } \\
\text { we really believe in? (UK3) }\end{array}$ & $\begin{array}{l}\text { I think it's a question of survival or } \\
\text { it's a question of the identity of an } \\
\text { institution, a public education } \\
\text { institution today. But I think for } \\
\text { many people it's still an add-on } \\
\text { (PT1). }\end{array}$ \\
\hline & $\begin{array}{l}\text { International students are important to } \\
\text { us and numbers are dropping at the } \\
\text { moment. So it's important that we } \\
\text { reverse that. Of course there is a } \\
\text { financial imperative to do that, but if } \\
\text { we can't continue to have international } \\
\text { students here it washes away the very } \\
\text { foundations of the university, and it } \\
\text { washes away a strategic objective of } \\
\text { having an international experience } \\
\text { (UK9) }\end{array}$ & $\begin{array}{l}\text { Internationalisation has had a very } \\
\text { important role in the culture of the } \\
\text { institution, especially within the late } \\
1980 \text { s and early } 1990 \text { s and the } \\
\text { development of research lines in } \\
\text { Portugal. International Education } \\
\text { came later with the European } \\
\text { mobility programmes, so Erasmus, } \\
\text { Lingua, the ECTS system (PT2) }\end{array}$ \\
\hline $\begin{array}{l}\text { Geographical } \\
\text { scope }\end{array}$ & $\begin{array}{l}\text { There is this international aspect of } \\
\text { really developing partnerships } \\
\text { institutions, these being universities } \\
\text { such as American universities, Chinese } \\
\text { universities. Sometimes, the } \\
\text { universities see it as some kind of } \\
\text { engagement, as a partnership, or } \\
\text { sometimes, it might be institutional } \\
\text { partnerships, where there is an interest } \\
\text { in developing partnership across the } \\
\text { university (UK 3) }\end{array}$ & $\begin{array}{l}\text { Internationalisation is focused in } \\
\text { several geographic areas in Europe. } \\
\text { Europe is a very strong network } \\
\text { because it does still finance lots of } \\
\text { research. So, a very strong European } \\
\text { dimension. And also a very strong } \\
\text { dimension with the Portuguese- } \\
\text { speaking countries: Brazil, Africa, } \\
\text { Timor and an increasing interest in } \\
\text { places like Chile and India (PT2) }\end{array}$ \\
\hline
\end{tabular}

The viewpoints in Table 3Table 3 show that the individual rationales for internationalising $\mathrm{HE}$ at the case study institutions are strongly bound to financial imperatives and to student recruitment, as emphasised by interviewees UK3, UK 9

(Row 1 and 2, respectively) and interviewee PT1 (Row 1). Yet, a stronger economic rationale for internationalisation was apparent in the British institution

In the Portuguese case study, and Portuguese HE in general, academic, cultural and political rationales have played a major part in the first efforts to internationalise Portuguese HE from the mid-1980s onwards via EU structural funds (PT2, Row 1), with financial imperatives expected to gain ground in the coming years given the recent introduction of full-cost tuition fees to degree-seeking students who want to study in 
Portugal. ${ }^{1}$ This measure affects, in particular, the internationalisation strategizing between public Portuguese tertiary education and Portuguese-speaking countries, which has been so far predominantly marked by cultural and intergovernmental rationales through the sharing of a common language and heritage.

In the UK, the recruitment of fee-paying international students has been an established feature of British HE since the 1980s, with degree-seeking student flows representing an enormous contribution to the national economy. This is reflected in the comments of case study 1 interviewees, with two participants indicating that financial drivers underpin a perceived overreliance on international student recruitment (UK3; UK9). Another respondent noted that one of the university campuses is strategically positioned to attract international students and to provide access to strategic multinational business partners:

"Part of the thinking behind the X Campus was that this location offered strategic positioning to attract international students to the UK and to provide access to strategic multinational business partners based in the city." (UK7)

Finally, interviewees demonstrated an understanding of the importance of successful partnerships with specific world regions or countries driving internationalisation efforts. Despite individual geo-political strategizing, both cases disclosed the shift from cooperation to competition whilst deeming BRIC countries as an emerging market for IoHE.

${ }^{1}$ The XIX Portuguese Democratic Government introduced in 2014 the longed-for International Student Status which fixes a special regime for international student access to undergraduate and integrated Master's studies in public HEIs in Portugal. 
Interviewees' perceptions from both case studies highlight two important paradigms of internationalisation with a perceived shift from cooperation to competition in the internationalisation of higher education in Europe (Egron-Polak, 2012; Seeber et al., 2016; Hazelkorn, 2016).

Stakeholders reinforced the view that research performance indicators are still regarded as evidence of institutional success in internationalisation and a proxy for institutional development.

\footnotetext{
"So, my personal ambition is frustrated by the lack of institutional and national ambition in this field, but I understand also that the universities have to start their internationalisation processes by its strong research profile. It's because of research that universities are evaluated internationally, it's because of citations, it's because of the numbers of publications per head...these are the indicators that matter in the international context" (PT2).
}

"There's a little bit of institutional anxiety around the fact this university is within an elite research-intensive universities' group but it's not towards the middle or towards the top in terms of the rankings, and again this drives an awful lot of institutional strategizing around internationalisation which is a lot about rankings and maintaining rankings" (UK2).

A differentiating factor for the Portuguese university is the dissemination of research and provision of programmes taught in English as a measure of successful internationalisation practices, in line with the reality of many other non-Englishspeaking countries worldwide (e.g. Hultgren, 2014).

A common denominator shaping the internationalisation practices of both case studies and many other post-secondary institutions worldwide, academic mobility assumes different forms in the two institutions. As discussed throughout Theme 1, international student recruitment is a long-standing feature of British HE, shaping not 
only the profile of its institution as a whole but also of individual academic units.

Naturally, postgraduate students assume more prominence in the British case study over the Portuguese one where student exchange is deeply bound to the role of the EU in instigating the international agendas of Portuguese post-secondary institutions. These stances are illustrated by the viewpoints of interviewees UK2 and PT2.

\footnotetext{
"As a school this is probably the most international school in the Faculty, certainly in terms of students. The vast majority of postgraduate taught students, a large majority nationally are international. International here being both EU and non-EU. In terms of the staff, we have a pretty international profile. And that's in line the faculty where a quarter of the university staff are non UK" (UK2).
}

\footnotetext{
"The role of European credit schemes has been essential in the internationalisation of the university. These are flagship programs, especially Erasmus. And it's due to these programs that the university has made contact with universities for the purposes of exchange and education; it's through these programs and because of these programs that we have been able to set up something like three hundred bilateral exchange agreements." (PT2)
}

To summarise, findings illustrate that despite the growing concern over the development of evaluation systems to monitor internationalisation practices, the effectiveness of IoHE tends to be reduced to instrumentalities, global rankings and cross-border education. As a consequence, internationalisation processes can easily remain a 'symbolic' rather than 'transformative' influence on the culture and values of the institution and its academic community (Turner \& Robson, 2008). This is evident in the concerns of respondents who perceived a greater institutional focus on enhancing research impact and accountability rather than on the international aspects of the curriculum, teaching practices and student experiences; discussed next. 
Theme 3 describes the relative importance of internationalised curricula and/or pedagogies for IaH. Interviewees from both institutions acknowledged the added-value of embedding intercultural perspectives into curricula and teaching/learning processes.

\footnotetext{
"Internationalisation is also having an international dimension to all of our study programs so our graduates can get work or study in a globalised society. So, it's not only having ... an international presence on campus it's also giving an international dimension to the education that we are giving to our own young people" (PT1)
}

Embedding intercultural learning into exchange programme design and delivery was also emphasised.

\footnotetext{
"It would be very interesting to offer intercultural learning as a feature of Campus Europae. I think probably it will require convincing the language teachers to change the way they are teaching the students (...) about the way the host country language is taught"(PT3).
}

Interviews at the British university also acknowledge the relevance of internationalised curricula, but reported that little emphasis is currently put on international aspects of the curriculum, with learning and teaching related issues occupying a peripheral role in staff meetings.
"When I go to faculty events, representing the school, the amount of time dealt to talking about international aspects of the curriculum is relatively small. It's unusual...within a 2 to $3 \mathrm{hr}$ meeting we typically spend 5-10 min talking about some aspects of the internationalisation of the curriculum." (UK2)

Interviewees emphasised a lack of clarity surrounding the term ' $\mathrm{IaH}$ ', and how it relates to internationalisation of the curriculum. They reported a perception that while university staff were aware of the term, they were unsure about its exact meaning. 
"There's only a minimal understanding of IaH. The term it is certainly used by the university, but I would think the majority of university staff would not know what you mean by that term." (UK2)

“There isn't a focus on IaH in the university's strategy. It's difficult because there are several definitions, would you define from a student or academic perspective?" (UK3)

A similar lack of clarity concerns the terms intercultural learning and/or competencies which were perceived as rather vague. There was also consensus among interviewees that the diversity of the academic community (both of students and staff) was not adequately harnessed as a learning resource.

\section{Theme 4: Professional development}

Interviewees gave their perceptions of staff roles and responsibilities within institutional internationalisation processes, as well as of professional development opportunities to support the delivery of intercultural and/or internationalised curricula.

The need for roles and responsibilities regarding internationalisation to be clearly delineated was raised by UK participants. There was a sense that the responsibility to implement institutional strategies was not attributed to particular staff, along with the acknowledgement that internationalisation activities in teaching were largely dependent on individual efforts and personal initiative.

\footnotetext{
"They are definitely not clearly defined, only at the top level, but when it comes to school level they wouldn't be clearly defined. There might be someone in charge of internationalisation, but it often comes down to individual interests or needs." (UK3).

"The cultural diversity of the academic community is a fantastic resource but it's not actively promoted or recognised. One thing I think is probably worth saying is that thinking about my motivation when I come across international students, I
} 
lived abroad for a year before I went to university, and so I have some understanding of being in a foreign country. In that sense, I am more unusual that other academics because I know how hard it can be to live and not having English as your first language" (UK1)

Nonetheless, some positive examples of effective roles were highlighted such as a post dedicated to the integration of international students (UK4).

All interviewees emphasised the importance of systems to reward and recognise individual efforts related to internationalisation, but also agreed that these were difficult to develop. Rather than financial reward, interviewees felt that these systems should include recognition of individual efforts through promotion processes and institutional awards (UK1 and UK5) and that roles needed to be adequately resourced.

Similarly, interviewees from the Portuguese case study stressed the need to prepare teaching staff to enact quality internationalisation processes that address teaching and learning practices. This resonates with academic literature drawing attention to the need to extend IoHE to the teaching profession (e.g. Kissock \& Richardson, 2010; Koziol, Greenberg, Williams, Niehaus, \& Jacobson, 2011; Moss, Manise, \& Soppelsa, 2012; Zhao, 2010). Globally-ready teachers are needed to deliver globally competent pedagogy:

\footnotetext{
"We've to inject international hormones into the university and I'm talking specifically about the internationalisation of our education programs which is also getting and training teachers to improve their international competences, so that we're on par with our partners across Europe." (PT2).
}

Having more intercultural and globally-ready teachers is important to build a bottom-up culture that actively involves different institutional actors in internationalisation processes and preparation of future generations of graduates: 
"I think that what we're doing is trying to build a culture from below and trying to involve more actors in that process" (PT1).

This suggests an understanding that internationalisation is dependent on the engagement of faculty and students. Institutional internationalisation strategies that assume that faculty are naturally engaged (UK5) may fail to tackle how internationalisation unfolds in practice (Almeida, 2015). This highlights the importance of both bottom-up and topdown approaches in relation to the social contexts and agents that underpin IaH processes (Ibid), if the goal is to think holistically about internationalisation.

\section{Theme 5: Perceptions of students' (on-campus) experience}

Although not specifically labelled as $\mathrm{IaH}$, a range of cultural activities are regularly organised on campus by both institutions that aim to provide a more internationalised and inclusive domestic learning environment. However, these initiatives appear to be aimed mainly at international students (e.g. excursions, 'Christmas gatherings' and 'buddy' schemes). Some initiatives more specifically aimed at 'home' students do exist, e.g. a student ambassador scheme for returning exchange students at the British institution and a Language Tandem project at the Portuguese institution. Key intercultural activities like these can be discontinued unless they are fully institutionalised (Almeida, Fantini, Simões, \& Costa, 2016).

A perceived lack of integration of 'home' and 'international' students was identified as a key challenge for IaH in both universities. International students appear to find it difficult to instigate and maintain meaningful social contact with their domestic peers. Interviewees acknowledged the tendency among students to cluster around those perceived as similar (Table 4Table 4). 
Table 4 - Theme 5: Descriptors and excerpts.

\begin{tabular}{|l|l|l|}
\hline Descriptors & Case 1 & Case 2 \\
\hline $\begin{array}{l}\text { Divide between international } \\
\text { and home students }\end{array}$ & $\begin{array}{l}\text { I think what we haven't yet } \\
\text { managed to actually fully } \\
\text { integrate the various groups } \\
\text { with each other, but also within } \\
\text { the international group. We do } \\
\text { see the tendency that western } \\
\text { European people stick together, } \\
\text { Chinese people or Asian people } \\
\text { stick together ... there's lack of } \\
\text { integration. (UK3) }\end{array}$ & $\begin{array}{l}\text { I think that an integration program } \\
\text { which would be designed } \\
\text { specifically to bring both student } \\
\text { foreign students and there's the } \\
\text { to break down that barrier, } \\
\text { because you can't force people } \\
\text { into relationships. (PT1) }\end{array}$ \\
\hline Role of student services & $\begin{array}{l}\text { An intelligent or smart strategy } \\
\text { would be one that incorporates } \\
\text { the activities of the Erasmus } \\
\text { Student Network, as } \\
\text { complementary or even as } \\
\text { inherent in the study programs } \\
\text { of the university. So, students } \\
\text { would be encouraged to engage } \\
\text { in the Erasmus Student Network } \\
\text { or in the student union as a } \\
\text { university philosophy. (PT1) }\end{array}$ & $\begin{array}{l}\text { Student Unions would have a } \\
\text { huge role to play in IaH because } \\
\text { university isn't just about coming } \\
\text { to lectures. Whenever you leave } \\
\text { university, you never think back } \\
\text { and think 'Oh, remember that } \\
\text { exam I did?' You think the } \\
\text { societies you were in, the sports } \\
\text { you played, the trips you went } \\
\text { on....And that's exactly why } \\
\text { everything we do is catered to } \\
\text { make sure that everybody can } \\
\text { take part. (UK6) }\end{array}$ \\
\hline
\end{tabular}

There was also acknowledgement that international students generally appear keen to integrate but that home students can be indifferent. Accommodation services were identified as key in the integration of students from different backgrounds, but attempts to actively 'mix' students reportedly often failed.

The finding that student services make a differentiated contribution to the attractiveness of European HE is in line with results from the Trends report (Sursock, 2015) and other academic literature that emphasises the possibilities and limitations of interculturality on HE campuses (Almeida et al., 2016; Dervin \& Layne, 2013; Leask, 2009; Schweisfurth \& Gu, 2009):

International student associations like the Erasmus Student Network (ESN, www.esn.org), and Local Student Unions play a fundamental part in ensuring home and international students develop intercultural awareness and mutual relationships on 
campus (Almeida et al., 2016). These enhanced interaction and inclusivity ideals are at the heart of IaH practices, with student associations playing a key role in bridging the gap between the cross-border and 'at home' pillars of internationalisation and the formal and non-formal dimensions of IaH (Ibid).

\section{Implications for enacting IaH practices}

In this section, we build on the discussion previously outlined to identify relevant factors to understanding enacting and communicating IaH practices in HE institutions. To this end, we subsume the five themes and underlying factors into a concept map that can be seen as a starting point to mapping out the relationships between the concepts and underlying descriptors at the heart of IaH (Figure 1Figure 1). This conceptual map assumes that not only IoHE but also IaH should address three interrelated dimensions Organisation, Curriculum, and People - in line with the framework developed by the UK Higher Education Academy for IoHE in relation to learning and teaching (HEA, 2014). 


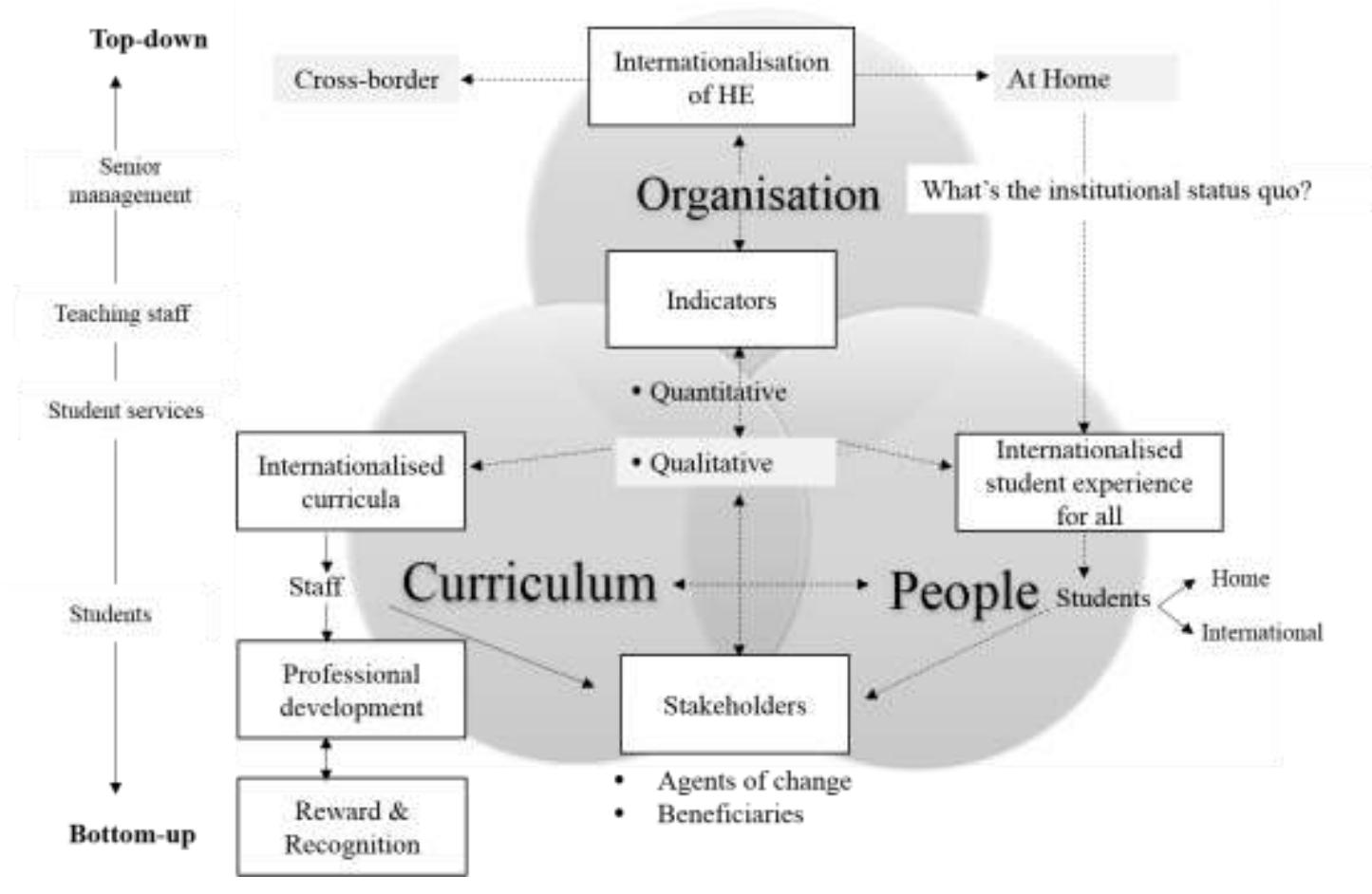

Figure 1 - Conceptual map of Internationalisation at Home.

As illustrated by Figure 1Figure 1, understanding and enacting internationalisation, in general, and IaH practices, in particular, requires the review of institutional, individual and curriculum dimensions. As the two case studies demonstrated institutional strategizing affects how its social agents understand and contribute to $\mathrm{IaH}$, with regard to teaching, learning and research. Enacting an IaH agenda requires, therefore, that internationalisation efforts are viewed as qualitative processes that offer more internationalised and inclusive experiences for all, especially for the non-mobile majority. This entails the intertwinement of formal and non-formal dimensions of an Internationalised Curriculum but also professional development opportunities and recognition systems to assist and incentivise academic staff to engage with, model and deliver these experiences for students.

It should be noted that whilst the formal dimension of the curriculum is inextricably linked to staff and institutional perspectives on teaching and learning, the 
non-formal realm builds strongly on student services and student associations. Although extra-curricular activities are not always fully integrated, students are the ultimate beneficiaries (Beelen and Jones, 2015). The intercultural benefits gained from these efforts involve, among other aspects, the integration of domestic and international student bodies, hence our representation of students as 'home' and 'international', with international representing both incoming degree and credit- seeking students. Notwithstanding the centrality of the 'Student Experience' in IaH, students should not be regarded as the sole catalysts of change. A broad range of stakeholders in an Organisation, need to be actively involved in top-down and bottom-up processes. People will always be the key drivers effecting changes in their range of social contexts. Opportunities for the academic community to develop an international outlook need to be driven from the bottom-up and supported top-down, offering opportunities for personal and academic development to students and staff alike.

\section{Conclusions and recommendations}

In this paper, we argue that although $\mathrm{IaH}$ is now discussed as an issue of key strategic importance in Europe, there remains a lack of consensus within and across institutions about how it should be defined and implemented (Sursock, 2015).

Although the research objectives of our study were examined through only two institutional case studies, their intertwinement and range of social agents they represent demonstrate that HE institutions share several common concerns (sometimes, blockers, sometimes enablers) with respect to IoHE, in general, and IaH, in particular. We have built on the viewpoints of different stakeholders to offer an empirical understanding of $\mathrm{IaH}$, by contextualising it in the words of those that are both the agents of change and beneficiaries of a sustainable IaH agenda. To this end, we subsumed the five analytical 
themes that accrue from our data into a concept map (Figure 1) that might serve as a flexible framework to assist other institutions to review how IaH is understood, enacted and communicated as part of the ongoing development of their approach to internationalisation. This framework is organised into three interrelated dimensions (Organisation, Curriculum and People) on the assumption that IaH should be part of a coherent narrative of the overarching philosophy, mission and curricula of HE institutions. This is of particular relevance in light of our findings which show that despite recognition of IaH and some developments in both institutional case studies, the learning and social benefits of an 'internationalised university experience for all' (particularly for the non-mobile) are not systemically prioritised in institutional agendas for internationalisation.

Further empirical research on IaH would provide additional insights into how this dimension of internationalisation is being operationalised across other European HE institutions. A wider range of stakeholder and institutional perspectives would of course add to our analysis. Nevertheless, we hope that this study can also be a call for further empirical work on IaH so that it is not only debated but systematically implemented in a greater number of institutions.

We propose that review and development of IaH policies and practices is particularly timely, not only because international and intercultural experiences are important to the development of employability skills for the globalized workplace (Beelen and Jones, 2015). They are also important enablers of democratic and socially responsible participation in culturally diverse societies. At the level of the institution, our findings suggest that internationalisation strategies remain broad and vague (Pashby and Andreotti, 2016) leading to uneven engagement with rationales, approaches and strategies. More comprehensive IaH strategies are necessary to address any financial, 
structural or communication blockages to progress; to build on the views of stakeholders on how IaH unfolds in practice; and to deploy expertise to embed explicit intercultural and international dimensions into the university experience.

For institutions focused on enhancing their position, prestige and profile in a competitive international education market (Seeber et al., 2016), IaH relates to, but can be seen to extend the scope of internationalisation of the curriculum. IaH can communicate that internationalisation is a key element of the institution's cultural capital (Lumby and Foskett, 2016); that it seeks to develop graduates and employees who are 'responsible, capable, compassionate, self-aware, ecoliterate, [and] cosmopolitan' (Haigh and Clifford, 2010). It can demonstrate the importance attributed to the non-market social and collective benefits of HE (de Wit et al., 2015; Prieto-Flores et al., 2016) and the contribution of the institution 'to stable, cohesive and secure environments.....cultural tolerance, and enhanced democracy' (Marginson, 2014, p.61).

Further empirical research would be welcome to provide insights into how this dimension of internationalisation is being operationalised across other European HE institutions to address the ethical, social, cultural and academic challenges facing the sector.

\section{References}

Almeida, J. (2015). European student mobility and intercultural learning at a Portuguese university. (Unpublished doctoral thesis). University of Aveiro. Aveiro.

Almeida, J., Fantini, A. E., Simões, A. R., \& Costa, N. (2016). Enhancing the intercultural effectiveness of exchange programmes: formal and non-formal educational interventions. Intercultural Education, 27(6), 517-533. doi:10.1080/14675986.2016.1262190

Altbach, P.G (2013). Advancing the national and global knowledge economy: the role of research universities in developing countries. Studies in Higher Education. 38, (3), 316-330.

Amaral, A., \& Magalhães, A. (2002). The external role of emergent stakeholders in European higher education governance. In A. Amaral \& B. Karseth (Eds.), 
Governing higher education: National perspectives on institutional governance (pp. 1-12). Dordrecht: Kluwer Academic Publishers.

Barker, M. C., Mak, A. S. (2013). From classroom to boardroom and ward: Developing generic intercultural skills in diverse disciplines. Journal of Studies in International Education, 17 (5), 573-589

Bedenlier, S. and Zawacki-Richter, O. (2015) Internationalization of Higher Education and the Impacts on Academic Faculty Members. Research in Comparative and International Education, 10 (2), 185-201

Beelen, J. and Jones, E. (2015) Re-defining 'internationalisation at home' p.59-72 in A.Curaj, L. Matei, R. Pricopie, J. Salmi, P.Scott (Eds.) The European Higher Education Area. Dordrecht: Springer

Boyatzis, R. E. (1998). Thematic analysis and code development. Transforming qualitative information. Thousand Oaks, CA: Sage.

Castro, R., Rosa, M. J., \& Pinho, C. (2015). A Model for Stakeholders' influence on internationalization: A contribution from the Portuguese, Brazilian, and Dutch Cases. Journal for Studies in International Education, 19(2), 160-181.

Corden, A. and Sainsbury, R. (2006) Using verbatim quotations in reporting qualitative social research: researchers' views. ESRC 2136. ISBN: 978-1-871713-98-5.

Crowther, P., Joris, M., Otten, M., Nilsson, B., Teekens H., Wächter, B. (2000) Internationalisation at Home. A Position Paper. European Association for International Education (EAIE). Amsterdam: Drukkerij Raddraaier.

de Wit, H., Hunter, F., Howard, L. and Egron-Polak, E. (2015). The Internationalisation of Higher Education. Brussels: the European Parliament, Committee on Culture and Education.

Dervin, F., \& Layne, H. (2013). A guide to interculturality for international and exchange students: An example of hostipitality. Journal of Multicultural Discourses, 8(1), 1-19. doi:10.1080/17447143.2012.753896

EAIE, 2016 Spring Forum: Internationalisation in a Conflicted World. http://www.eaie.org/eaie-resources/library/publication/Forum-Magazine/2016spring-forum

Egron-Polak, E. (2012) Affirming Academic Values in Internationalization of Higher Education: A Call for Action. Global Higher Education, April 19, 2012.

EUA (2012) Mapping University Mobility of Staff and Students (MAUNIMO) (20102012) European Universities Association http://www.eua.be/activitiesservices/projects/past-projects/learning-teaching/mapping-university-mobilityof-staff-and-students.aspx

EUA (2013) Internationalisation in European Higher Education: European Policies, Institutional strategies and EUA support. European University Association http://www.eua.be/Libraries/highereducation/EUA_International_Survey.pdf?sfvrsn=0

European Commission (2013). European Higher Education in the World http://ec.europa.eu/education/policy/international-cooperation/worldeducation_en

European Commission. Europe 2020 Growth Strategy. http://ec.europa.eu/europe2020/europe-2020-in-anutshell/priorities/index_en.htm

European Parliament 19 Jan 2016 The role of intercultural dialogue, cultural diversity and education in promoting EU fundamental values http://www.europarl.europa.eu/sides/getDoc.do?type=TA\&reference=P8-TA2016-0005\&language $=\mathrm{EN}$ 
Fereday, J., \& Muir-Chochrane, E. (2006). Demonstrating rigor using thematic analysis: A hybrid approach of inductive and deductive coding theme development. International journal of qualitative methods, 5(1), 80-92.

Freeman, E. R. (1984). Strategic management: A stakeholder approach. Boston: Pitman.

Haigh, M. and Clifford, V. (2010) Widening the Graduate Attribute debate: a Higher Education for Global Citizenship. Brookes Journal of Learning and Teaching. 2(5), 2010.

Harrison, N. (2015) Practice, problems and power in internationalisation at home: critical reflections on recent research evidence. Teaching in Higher Education, 20 (4). pp. 412-430. ISSN 1356-2517

Hazelkorn, E. 2016 Ed., Global Rankings and the Geopolitics of Higher Education London, Routledge.

Hénard, F., Diamond, L., Roseveare, D. (2012). Approaches to Internationalisation and Their Implications for Strategic Management and Institutional Practice. A Guide for Higher Education Institutions. Institutional Management in Higher Education. OECD, 2012.

Higher Education Academy. (2014). Framework for internationalising higher education Retrieved from https://www.heacademy.ac.uk

Higher Education Policy Institute (HEPI) (2017). The determinants of international demand for UK higher education. Final Report for the Higher Education Policy Institute and Kaplan International Pathways.

Hudzik, J.K. (2011). Comprehensive Internationalization: from Concept to Action. NAFSA, Washington D.C.

Hultgren, A.K. (2014). English language use at the internationalised universities of Northern Europe: Is there a correlation between Englishisation and world rank? Multilingua, 33, (3-4), 389-411.

IEREST: Intercultural Education Resources for Erasmus Students and their Teachers 2012-2015. http://www.ierest-project.eu/index.html

Inan, A., Wick, D., van Liempd, H.G., Fastner, M. (2014). Internationalisation with Integrity: modelling a new approach. European Association for International Education, 25 July 2014. http://www.eaie.org/blog/internationalisation-withintegrity/

Jones, E., and Killick, D. (2013). Graduate Attributes and the Internationalized Curriculum: Embedding a Global Outlook in Disciplinary Learning Outcomes." Journal of Studies in International Education.

Jones, E. (2014). Should internationalisation begin at home? International Focus 100. Universities UK. London: Universities UK.

Kissock, C., \& Richardson, P. (2010). Calling for action within the teaching profession. It's time to internationalize teacher education. Teacher Education, 21(1), 89-101.

Knight, J. (2004). Internationalization remodeled: Definitions, rationales, and approaches Journal of Studies in International Education, 8(1), 5-31.

Knight, J. (2012). Concepts, rationales, and interpretive frameworks in the internationalization of higher education. In D. K. Deardorff, H. De Wit, J. D. Heyl, \& T. Adams (Eds.), The Sage handbook of international higher education (pp. 27-42). Thousand Oaks, CA: Sage.

Koziol, S., Greenberg, J., Williams, L., Niehaus, E., \& Jacobson, C. (2011). Internationalizing teacher education. Paper presented at the International Conference for Education for Teaching, Glasgow. 
Leask, B. (2009). Using formal and informal curricula to improve interactions between home and international students. Journal of Studies in International Education, 13(2), 205-221. doi:10.1177/1028315308329786

Leask, B. (2015). Internationalising the curriculum. London: Routledge.

Lumby, J. and Foskett, N. (2016) Internationalization and Culture in Higher Education. Educational Management Administration \& Leadership. 44(1), 1-17 DOI: $10.1177 / 1741143214549978$

Mak, A. (2010) Enhancing Academics' Capability to Engage Multicultural Classes and Internationalize at Home. International Journal of Teaching and Learning in Higher Education, Volume 22, Number 3, pp. 365-373.

Marantz- Gal, A. (2016) Not just teaching, but peace-ing. Spring Forum 2016 Internationalisation in a conflicted world http://www.eaie.org/eaieresources/library/publication/Forum-Magazine/2016-spring-forum

Marginson, S. (2014) Higher Education and Public Good in P. Gibbs and R. Barnett (eds.), Thinking about Higher Education, 53-69. DOI: 10.1007/978-3-31903254-2_5, (C) Springer International Publishing, Switzerland.

Marginson, S. (2017) Higher education - The key to greater freedom. University World News, March 2017, Issue No.449.

Moss, D., Manise, J., \& Soppelsa, B. (2012). Preparing globally competent teachers. Background Paper for the Council for the Accrediation of Educator Preparation (CAEP) comissioners. Retrieved from http://www.nafsa.org/epubs

Nilsson, B. (2003) Internationalisation at Home from a Swedish Perspective: The Case of Malmö. Journal of Studies in International Education, 7 (1), 27-40. DOI: $10.1177 / 1028315302250178$

Pashby, K. \& Andreotti, V. (2016) Ethical internationalisation in higher education: interfaces with international development and sustainability. Environmental Education Research, 22, (6)771-787, DOI: 10.1080/13504622.2016.1201789

Prieto-Flores, O., Feu, J. and Casademont, X. (2016) Assessing Intercultural Competence as a Result of Internationalization at Home Efforts: A Case Study from the Nightingale Mentoring Program. Journal of Studies in International Education, 20(5) 437-453.

Schweisfurth, M. \& Gu, Q., (2009). Exploring the experiences of international students in UK Higher Education: possibilities and limits of interculturality in university life. Intercultural Education. 20(5), 463-473

Seeber, M., Cattaneo, M., Huisman, J., Paleari, S. (2016) Why do higher education institutions internationalize? An investigation of the multilevel determinants of internationalization rationales. Higher Education, 72:685-702 DOI 10.1007/s10734-015-9971-x

Sursock, A. (2015). Learning and teaching in European Universities. European University Association Retrieved from http://www.eua.be/publications/

Tierney, W.G. and Lanford, M. (2016) Conceptualizing Innovation in Higher Education Chapter 1, 1-40 in M.B. Paulsen (ed.), Higher Education: Handbook of Theory and Research, DOI 10.1007/978-3-319-26829-3_1

Turner, Y., \& Robson, S. (2008). Internationalizing the university: An Introduction for university teachers and managers. London: Continuum Press.

UKCISA (2016). International Students in the UK. https://institutions.ukcisa.org.uk/Info-for-universities-colleges--schools/Policyresearch--statistics/Research--statistics/International-students-in-UKHE/\#International-\%28non-UK\%29-students-in-UK-HE-in-2015-16. accessed 03 March 2017. 
Urban, S.L., and Palmer, L.B. (2014). International Students as a Resource for Internationalization of Higher Education. Journal of Studies in International Education 18(4): 305-324.

Wächter, B. (2003). An Introduction: Internationalisation at Home in Context. Journal of Studies in International Education, 7 (1), 5-11. DOI: $10.1177 / 1028315302250176$

Yemini, M. and Sagie, N. (2016). Research on internationalisation in higher education: exploratory analysis. Perspectives: Policy and Practice in Higher Education, 20, 2016, 2-3. http://dx.doi.org/10.1080/13603108.2015.1062057

Yin, R. K. (2014). Case study research design and methods (5th ed.). Thousand Oaks, CA: Sage.

Zhao, Y. (2010). Preparing Globally Competent Teachers: A New Imperative for Teacher Education. Journal of Teacher Education, 61(5), 422-431 doi:doi.org/10.1177/0022487110375802

7,454 words including refs 